Richards, B.S. ; Capão, D. ; Schäfer, A.I. ; (2008) Renewable energy powered membrane technology 2 The effect of energy fluctuations on performance of a photovoltaic hybrid membrane system,

Environmental Science \& Technology, 42(12); 4563-4569.

DOI: $10.1021 / \mathrm{es} 703157 \mathrm{n}$

\section{Renewable energy powered membrane technology. \\ 2. The effect of energy fluctuations on performance of a photovoltaic hybrid membrane system}

B.S. Richards ${ }^{1, *}$, D.P.S. Capão ${ }^{1}$, A.I. Schäfer ${ }^{2}$

${ }^{1}$ School of Engineering and Physical Sciences, Heriot-Watt University, Edinburgh, EH14 4AS, United Kingdom

${ }^{2}$ School of Engineering and Electronics, The University of Edinburgh Edinburgh, EH9 3JL, United Kingdom

\section{Submitted to}

Environmental Science and Technology

\section{December 2007}

Revisions submitted February 2008

* Corresponding author: Bryce Richards. Email: B.S.Richards@hw.ac.uk, Ph +44 131451 3614, Fax +44 131 4513129

\section{Abstract}

This paper reports on the performance fluctuations during the operation of a batteryless hybrid ultrafiltration - nanofiltration / reverse osmosis (UF-NF/RO) membrane desalination system powered by photovoltaics treating brackish groundwater in outback Australia. The renewable energy powered membrane (RE-membrane) system is designed to supply clean drinking water to a remote community of about 50 inhabitants. The performance of the RE-membrane to a remote community of about 50 inhabitants. The performance of the RE-membrane
system over four different solar days is summarised using four different NF membranes system over four different solar days is summarised using four different NF membranes
(BW30, NF90, ESPA4, TFC-S), and examined in more detail for the BW30 membrane. On an Australian spring day, the system produced $1.1 \mathrm{~m}^{3}$ of permeate with an average conductivity of $0.28 \mathrm{mS} . \mathrm{cm}^{-1}$, recovering $28 \%$ of the brackish $\left(8.29 \mathrm{mS} . \mathrm{cm}^{-1}\right.$ conductivity) feedwater with an average specific energy consumption of $2.3 \mathrm{kWh} . \mathrm{m}^{-3}$. The RE-membrane system tolerated large fluctuations in solar irradiance $\left(500-1200 \mathrm{~W} \cdot \mathrm{m}^{-2}\right)$, resulting in only small increases in the permeate conductivity. When equipped with the NF90 (cloudy day) snd ESPA4 (rainy day) membros, the system was able to produce $1.36 \mathrm{~m}^{-3}$ (Cloud $0.85 \mathrm{~m}^{-3}$ ) and ESPA4 (rainy day) good quality permeate, respectively. The TFC-S nembrane was not able to produce adequate water quality from the bore water tested. It is concluded that batteryless operation is a simple and robust way to operate such systems under conditions ranging from clear skies to medium cloud cover.

\section{Keywords}

Nanofiltration, reverse osmosis, ultrafiltration, solar energy, batteryless operation, energy fluctuation. 
Richards, B.S. ; Capão, D. ; Schäfer, A.I. ; (2008) Renewable energy powered membrane technology 2 The effect of energy fluctuations on performance of a photovoltaic hybrid membrane system,

Environmental Science \& Technology, 42(12); 4563-4569.

DOI: $10.1021 /$ es703157n

\section{Introduction}

Renewable energy-powered nanofiltration / reverse osmosis (NF/RO) desalination systems (RE-membrane systems) are considered one of the most promising technology combinations for the sustainable provision of clean drinking water, particularly for small-scale systems in remote areas where an electricity grid does not exist. In particular, photovoltaic (PV) powered membrane filtration systems have considerable potential in areas where a synergistic relationship exists between the amount of solar irradiance received and the availability of brackish groundwater (1).

The majority of RE-membrane systems tend to use batteries to avoid energy fluctuations which cause variations in pressure and flow - and to enable continuous operation. While energy storage enables a RE-membrane system to produce a known amount of water at the desired quality, the use of batteries results in several problems. Firstly, the charge-in/chargeout efficiency of a typical deep-cycle lead acid battery is $75-80 \%$ (2), resulting in a significant loss in system efficiency. Subsequently, a $20-25 \%$ larger PV array is needed, substantially increasing system cost. Secondly, batteries both perform worse and degrade faster at higher temperatures. Specifically, with increasing operating temperature, the following occurs (2): a) the battery capacity decreases; b) the charge efficiency decreases; and, c) the self discharge rate increases. This has resulted in battery banks requiring and, c) the self disc a the batery capcily replacement in af ans a considerably to maintenance costs (3). Thirdly, even for a long battery-life of five years - representing over 1500 charge-discharge cycles - the battery bank will require replacement since PV systems are typically designed to have a 20 -year life. Thus, in remote regions that lack adequate disposal/recycling facilities, improper disposal can create further environmental hazards due to limited recycling (4) and increase the life-cycle cost of the system.

For these reasons, it is interesting to investigate the performance of batteryless RE-membrane systems. However, while directly-coupled PV-powered water pumping systems operate very successfully without energy storage (5), relatively little is known about the consequences of variable operation (flow, pressure) on NF and RO membrane systems $(1,6)$.

Gocht et al. (7) performed preliminary experiments to determine the technical feasibility of transiently operated RO system. The pressure was increased linearly at a rate of $180 \mathrm{bar}^{\mathrm{min}}{ }^{-1}$ and also step-wise (from 10 bar to 60 bar), while the flux and salt rejection were measured as a function of time. Although no detailed results were presented, Gocht et al. (7) concluded that nothing was observed that ruled out the transient operation of a RO membrane system. Pestana et al. (8) also agree with this conclusion, stating that $\mathrm{RO}$ membranes can function in a without deteriorating, although additional study of the membranes to determine if long-term wear occurs and the reasonable operating window for such fluctuations to be sustainable.

There are some reports in the literature on batteryless desalination systems powered by renewable energy, investigating the permeate quality throughout the day. The group of Infield et al. designed a batteryless RO desalination unit that could be powered by PV or wind energy $(3,6,9)$. The modelled performance for the PV-membrane system indicated a clean water production of $3.9 \mathrm{~m}^{3} \mathrm{~d}^{-1}$, with a maximum salinity of about $500 \mathrm{mg} \cdot \mathrm{L}^{-1}$ when operated with fedwater contining $34.3 \mathrm{gL}^{-1} \mathrm{NaCl}^{(9)}$. In experime the total product water with feedwater containing 3 acheved ic energy consumption (SEC) was found match the modelled data well - with a minimum value of $3.5 \mathrm{kWh} . \mathrm{m}^{-3}$ - the values obtained for permeate concentration were much greater then predicted, with an average of 1.1 g. $\mathrm{L}^{-1}$ over a two-day test. The high permeate concentration result was explained by the system being underpowered (using a $1.53 \mathrm{~kW}$ PV array instead of the of $2.4 \mathrm{~kW}$ design value), due to the test being performed in England during cloudy days; and, the low efficiency of the plunger pump. Further losses in efficiency also occurred due to the presence of two DC-AC inverters in the system.

A PV-powered RO desalination system was developed by Mathew et al. (10), based on a piston pump similar to that first presented by Keefer et al. (11). The excess energy contained in the brine stream - which is significant given the $\sim 0.5$ bar pressure drop across a RO membrane module - is fed back behind the piston to assist it on the upstroke. This allows a high-pressure to be maintained even during periods of low solar irradiance, simply by a reduction in feedwater flow. However, several problems have been encountered during field trials of this system in Australia, including fouling of the microfiltration (MF) pre-filters and cracking of the plastic pump case (10). No transient results of this system have been presented to date.

A different approach that relies solely on mechanical power was presented by Pritchard et al. (12) and Robinson (13). Both papers describe the design and operation of a wind-powered RO brackish-water desalination plant that uses a pressure vessel as a hydraulic accumulator to avoid working with fluctuating conditions in flow and pressure parameters. Thus, the feedwater is stored under pressure and released when a suitable pressure is achieved and so allowing the system to operate in a suitable range of flow and pressure. The system described different feed waters . For a feedwater concentration of $2 \mathrm{~g} \cdot \mathrm{L}^{-1}, 291 \mathrm{~L} \cdot \mathrm{d}^{-1}$ of permeate was produced at a recovery of $9.7 \%$ and an average salinity of $352 \mathrm{mg} . \mathrm{L}^{-1}$ (13). At a higher feedwater concentrations of $4 \mathrm{~g} . \mathrm{L}^{-1}$, the permeate production decreased to $197 \mathrm{~L} . \mathrm{d}^{-}$ ${ }^{1}$, while permeate salinity increased to an average of $564 \mathrm{mg} \cdot \mathrm{L}^{-1}(13)$ - fractionally above the $500 \mathrm{mg} . \mathrm{L}^{-1}$ total dissolved solids (TDS) value permitted by the Australian Drinking Water Quality (ADWG) guidelines (14). Finally, with the highest feedwater concentration (6 g.L $\mathrm{L}^{-1}$ ), the average permeate salinity increased to $1.14 \mathrm{~g} . \mathrm{L}^{-1}$, more than double the ADWG value.

Liu et al. (15) also described a similar wind-powered RO desalination plant working with a flow/pressure stabilizer controlled by a series of three valves, which allows the system to operate within a pressure range of $5.2-7.2$ bar. Experiments were performed treating feedwater with a concentration of: i) $3500 \mathrm{mg} \cdot \mathrm{L}^{-1}$ TDS at a feed flow ranging from $6-$ $17 \mathrm{~L} . \mathrm{min}^{-1}$ and $19 \%$ recovery; and ii) $2700 \mathrm{mg} . \mathrm{L}^{-1}$ TDS feedwater at a feed flow ranging from $0-14 \mathrm{~L} \cdot \mathrm{min}^{-1}$ and $23 \%$ recovery (15). In both experiments, excellent feed water quality of less than $150 \mathrm{mg} . \mathrm{L}^{-1}$ TDS was maintained.

Pestana et al. (8) designed a wind-powered seawater desalination plant with six membrane modules (Koch Fluid Systems TFC 2822-SS) for a maximum feed flow of $9.8 \mathrm{~m}^{3} \cdot \mathrm{h}^{-1}$ and an to regulate the pressure and flow as seen by the membranes. Although the authors mention that transient test (time periods of $1 \mathrm{~s}$ ) were performed no results of these tests were presented
$(8)$. $(8)$.

A further challenge for PV- and wind-membrane systems is preventing fouling of the NF or RO membrane during intermittent operation. Liu et al. state that such fouling is a major problem with an intermittent RO system and special care is required for feedwater pretreatment (15). Thomson et al. (9) confirm that during periods of inoperation, the feed flow 
Richards, B.S. ; Capão, D. ; Schäfer, A.I. ; (2008) Renewable energy powered membrane technology 2 The effect of energy fluctuations on performance of a photovoltaic hybrid membrane system,

stops but salt continues to penetrate the membrane until a potential equilibrium is met in the system. To address this problem, these authors suggested that an automated valve could be used to reject product water exceeding a threshold concentration, thus improving the overall permeate quality of the system. A small-scale PV-membrane system described in the during (10) emphasised in particilar the inpote during periods of inoperation, making feedwater pre-treatnent compulsory in such intermittently-operating systems. Such bio-fouling has been observed in a PV-membrane system being operated in central Australia for a period of four weeks when only MF pretreatment was used (10). Liu et al. (15) also commented on the importance of pre-treatmen in maximising system efficiency and extending membrane life.

The first paper of this series (1) describes a hybrid PV-membrane system that uses UF technology as pre-treatment without the use of batteries. This previous work aimed to identify optimal operating characteristics of the system when using four different membranes a single groundwater source in central Australia with a wtable power source (generatr). In the present work, the performance of this PV-membrane system was investigated over a number of solar
days, with energy fluctuations resulting in pressure and flow variations.

\section{Materials and Methods}

The operation of the PV-membrane system was described previously under controlled pressure and flow conditions (1). To investigate the effect of energy fluctuations for different membranes, a set point was determined by a back-pressure valve position, which under constant power operation provided a pressure of $7 \mathrm{bar}$ and a feed flow $300 \mathrm{~L}_{\mathrm{h}}^{-1}$. Those settings were established prior to each solar experiment (before sunrise) and then the system was then left to run with regular monitoring (both automated and manual) in place without any manipulation of the valve until the solar irradiance of the setting sun decreased to a point where the system shut down automatically. Permeate and concentrate were continuously recycled back into the feed tank throughout the experiment, thus maintaining the feed concentration value throughout the day. At the time of the central Australian field trials (October 2005), the su 6:06 and set again at about 18:30, location for this experiment (Pine Hill Station, Northern Territory: latitude $22^{\circ} 29^{\prime} \mathrm{S}$, longitude $133^{\circ} 0^{\prime} \mathrm{E}$ ) solar irradiance was lost at about 18:00 due to nearby hills shading the PV array late in the day. The nearest major town to this location is Alice Springs (180 km to the south), receives a yearly average of $6.2 \mathrm{kWh} \cdot \mathrm{m}^{-2} \cdot \mathrm{d}^{-1}(1993-2000$, measured at the local meteorological station (16), while in the month of October, average daily solar irradiance $(1993-2000)$ is $7.1 \mathrm{kWh} \cdot \mathrm{m}^{-2} \cdot \mathrm{d}^{-1}$ (16), $79 \mathrm{~mm}$ of rain fell (well above average) (17), and the average peak daytime temperature is $33^{\circ} \mathrm{C}(17)$

While several feedwaters were tested during this field trial, results presented in this paper are only from Pine Hill Station (18) as this water was the most challenging for the system in terms of salinity and trace contaminant content. The brackish bore water tested at Pine Hill

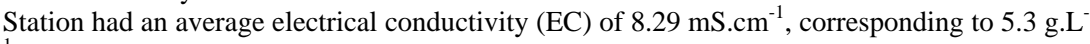
${ }^{1}$ TDS, with a more complete water analysis provided previously (1). New feedwater was added to the feedtank prior to each new experiment, and no adjustment of water quality was undertaken. The system was tested with four different 4 inch membranes (BW30, ESPA4, NF90, TFC-S) and the membrane specific parameters - flux, recovery, retention - and system

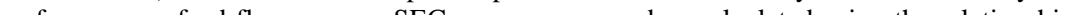
- were measured or calculated using the relationships described previously (1), while the transmembrane pressure (TMP) was defined erroneously
in the first paper of this series (1) and should appear as:

$$
T M P=\left(\frac{p_{3}+p_{2}}{2}\right)-p_{\text {permeate }}
$$

Although the membrane manufacturer Dow publishes maximum operating limits (pressure 41 bar and feed flow rate $3.6 \mathrm{~m}^{3} . \mathrm{h}^{-1}$ ) for their Filmtec series membranes of membranes (including the NF90 and BW30 used here) $(19,20)$, it is clear that fluctuations in pressure and flow are undesirable. Dow state that in order to avoid possible membrane damage - such as hydraulic shock - a proper start-up sequence is necessary with $(19,20)$ : i) pressure being increased gradually over $30-60 \mathrm{~s}$; - Thus, the most abrupt pressure variations allowed would be when going from 0 bar to 41.6 bar over a $30 \mathrm{~s}$ period $\left(83 \mathrm{bar}^{-\mathrm{min}^{-1}}\right)$ and - assuming that the crossflow velocity is linearly related to feed flow - a cross-flow velocity of $24 \mathrm{~m}^{3} \cdot \mathrm{h}^{-1} \cdot \mathrm{min}^{-1}$. The maximum feed flow and pressure are similar for the ESPA4 (21), while the TFC-S has a maximum pressure of 24.1 bar (22), which would result in a significantly lower variation in pressure. It is anticipated that PV-membrane system described here is operating the membranes within these limits, with pressure changes of $10 \mathrm{bar}^{\mathrm{min}}{ }^{-1}$ being observed during the field trials.

The PV panels were mounted on a single-axis solar tracker array guided by global positioning system (GPS), so that the panels follow the path of the sun (east-west) across the sky. This provides typically 30\% more power throughout the year compared to a non-tracking PV array. The altitude angle was set to the latitude angle ( $23^{\circ}$ north) - recommended for optimum yearround performance of a PV system - while the azimuth angle was aligned to true north. A maximum power point tracker (MPPT) ensures that the output of the PV panels (voltage $V$, current $I$ ) is well matched to that being drawn by the pump (the load). In addition to the sensors described previously (1), a temperature-compensated solar irradiance sensor (Mencke \& Tegtmeyer model Si-01TC, accuracy $\pm 5 \%$ ) was mounted in the same plane as the PV modules and supplied the datalogger with a signal of $1 \mathrm{~V}$ per $1000 \mathrm{~W} \cdot \mathrm{m}^{-2}$ of solar irradiance. modules and supplied the datalogger with a signal of $1 \mathrm{~V}$ per $1000 \mathrm{~W} . \mathrm{m}^{-2}$ of solar irradiance. Unfortunately, dedicated voltage and current sensors (Chenyang models CY-VZ02 and CY-
IZ04-E4) stopped working early in the field trip and the power consumption of the pump had to be read manually from the hand-held electronic interface (Mono-Pumps) to the pump. The power consumption of the pump was able to be calculated to an accuracy of better than $5 \%$. Due to periodic problems of the flow sensors used on the system during the field trip, the permeate and concentrate flows were also measured manually using a $2 \mathrm{~L}$ measuring cylinder and a stop-watch. All flows were measured two to three times per reading and an average of the readings taken, High-resolut pipe and the conductivity probe in a snall (50 $\mathrm{L}$ ) beaker in order to obtain an accurate reading in the shortest possible period of time (estimated to be about $0.5 \mathrm{sec}$ at a feed flow of
$400 \mathrm{~L} . \mathrm{h}^{-1}$ ).

It should be noted that the results are representative of many tests during a six week period, reflecting a total of 53 experiments on many water sources in six different locations (18). The borewater at Pine Hill represented the most challenging water to treat due to its high salinity and is the focus of experiments in this paper.

\section{Results and Discussion}

The daily average performance results for treating Pine Hill Station groundwater with the four different membranes are summarised in Table 1 . The main differences between the properties of the different membranes are flux and retention, which strongly influence other parameters such as cumulative permeate volume, permeate EC, concentrate EC, and SEC. Also, it should 
Richards, B.S. ; Capão, D. ; Schäfer, A.I. ; (2008) Renewable energy powered membrane technology 2 The effect of energy fluctuations on performance of a photovoltaic hybrid membrane system,

Environmental Science \& Technology, 42(12); 4563-4569. DOI: $10.1021 /$ es $703157 n$

be noted an additional consideration - the weather throughout the day - needs to be taken into account when comparing membrane performance. The weather conditions were best for the day the BW30 experiment was performed, with other days exhibiting significantly more heavy cloud and even rain, both of which were an unseasonal occurrence (17).

The RE-membrane system equipped with the BW30 membrane produced a total of $1106 \mathrm{~L}$ of drinking water at an average permeate EC of $0.28 \mathrm{mS} \mathrm{cm}^{-1}$ and an SEC of $2.3 \mathrm{kWh} \cdot \mathrm{m}^{-3}$. This membrane can produce drinking water of excellent quality (permeate TDS $<500 \mathrm{mg} . \mathrm{L}^{-1}$ ) over membrane can produce drinking water of excellent quality (permeate TDS $<500 \mathrm{mg}^{-L^{-1}}$ ) over a very wide range of operating conditions (1). Such a system would be able to supply a remote community of 50 people with about $20 \mathrm{~L}$ of drinking water per day each. Since the quality of water is significantly higher than required and could hence be mixed with UF permeate to increase total volume produced while remaining within the suggested guideline value or, alternatively, a membrane with lower retention could be used. In addition, given the low recovery (about 28\% in this trial) an additional amount of about $70 \%$ of the feedwater will have been physically disinfected in the UF process and is available at the higher salinity $\left(10.2 \mathrm{mS} \mathrm{cm}^{-1}\right)$ for other uses such as washing/hygiene or stock watering (1), which increases the allowance to a very comfortable level.

As shown in Table 1, on an overcast day the NF90 membrane produced a higher cumulative permeate volume $(1355 \mathrm{~L})$ than the BW30 membrane with a satisfactory average permeate EC $\left(0.52 \mathrm{mS} \mathrm{cm}^{-1}\right)$ and at a significantly lower SEC of $1.5 \mathrm{kWh} . \mathrm{m}^{-3}$. The ESPA4 membrane had previously produced the best SEC values when operated from a constant power source (1), however on the day of the solar experiment its performance was limited due to poor weather conditions. Although the RE-membrane system equipped with ESPA4 produced a total of $848 \mathrm{~L}$ of permeate volume throughout the day, the average permeate EC $(0.81 \mathrm{mS} . \mathrm{cm}$ $\left.{ }^{1}\right)$ was fractionally higher than the ADWG limit. This is simply due to the occurrence of

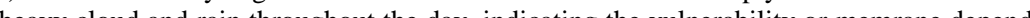
heavy clou a ran of RE-membrane syste conditions. Finally, the TFC membrane was not able to produce adequate water quality (permeate EC $2.12 \mathrm{mS}_{\mathrm{cm}} \mathrm{cm}^{-1}$ ) for the bore water tested, which confirms previous results (1). To facilitate further comparison, the performance of the RE-membrane system is given in Table 2 with the four different membranes when operating under very similar climatic conditions - bright sunshine near the middle of the day - with data being taken from the datalogger (instantaneous) and - when the flow sensors were not functional - supported by manually-determined values taken over a one minute interval. The increase in permeate flow rate from $122 \mathrm{~L}^{-1}$ with BW30, to $188 \mathrm{~L} \mathrm{~h}^{-1}$ with NF90, $241 \mathrm{~L} \mathrm{~h}^{-1}$ with ESPA4, and $287 \mathrm{~L}^{-1}$ with TFC-S can be clearly seen, indicating that the RE-membrane system could be expected to produce nearly twice as much permeate when using the ESPA4 membrane.

The remainder of the results in this paper describe the performance of the RE-membrane system equipped with the BW30 membrane and operating under fluctuating energy conditions. The BW30 membrane was chosen because of its ability to desalinate highly brackish feedwater (1). The solar irradiance incident upon the tracked PV modules on 7 October 2005 is plotted in Fig. 1(a). The sun rises at 6:06 and solar irradiance reaches $1000 \mathrm{~W} \cdot \mathrm{m}^{-2}$ by 10:00. Note that while $1000 \mathrm{~W} \cdot \mathrm{m}^{-2}$ is the reference value for terrestrial solar systems, higher values are possible during the middle of the day when the air-mass - the we noticeable peak in the solar irradiance just after midday. This is attributed to the disappearance of some very thin, high cloud (or dust particles in the air), which then re-appeared again about $1 \mathrm{~h}$ later again. Several thicker clouds pass during the afternoon causing large reductions in the solar irradiance for short periods of time (on the order of minutes). Fig. 1(a) shows the difference in solar irradiance collected from the one-axis tracked array (solid grey curve) used by the
RE-membrane system compared to a fixed north-facing PV array (dashed grey curve) at $23^{\circ}$ tilt angle (altitude). A numerical integration of the tracked solar irradiance curve yields $9.5 \mathrm{kWh} \cdot \mathrm{m}^{-2} \cdot \mathrm{d}^{-1}$ of solar irradiance being collected, $36 \%$ greater than from a fixed PV array of the same area $\left(7.0 \mathrm{kWh} \cdot \mathrm{m}^{-2} \mathrm{~d}^{-1}\right)$. At about $15 \cdot 30$, the solar irradiance begins to decrease as the sificantly longer and is fully lost behind the hills at about 18:00 prior to sunset. The average daily solar irradiance levels at this location for the month of October (1990 - 1998 satellite data) are $7.1 \mathrm{kWh} \cdot \mathrm{m}^{-2} . \mathrm{d}^{-1}(17)$. The amount of solar power generated - and then immediately consumed by the pump typically follows the solar irradiance. Fig. 1(a) shows the power consumption of the system, which is seen to fluctuate during the day due to the presence of clouds.

As soon as the PV array is producing sufficient power to start the pump ( $>50 \mathrm{~W})$ the feedwater is sucked through the submerged UF modules. The negative suction pressure is dependent on the power available for the pump and reaches a peak with full solar irradiance of about -0.6 bar, with slight fluctuations being observed during cloudy periods (not plotted). The varying UF pressure results naturally in a corresponding feed flow and the UF permeate is then pressurised with the pump for the desalination stage, as shown in Fig 1(b). While is then pressurised with the pump for the desalination stage, as shown in Fig 1(b). While
sensor problems occurred at the beginning of the day, the flow reaches a stable value of about sensor problems occurred at the beginning of the day, the flow reaches a stable value of about
$400 \mathrm{~L} \cdot \mathrm{h}^{-1}$ throughout most of the day (09:00 to 16:00). It is important to note that if power decreases then flow reduces, which reduces the crossflow velocity in the NF/RO module and hence increases the boundary layer thickness, thickness which is the accumulation of retained salts on the membrane surface. As a result the salt concentration at the membrane surface increases (at constant pressure), which results in an increase in salt diffusion across the membrane and hence decreased permeate quality. However, as the TMP also fluctuates with less permeate is produced at lower pressure given the pressure dependence of flux. This further reduces water transport and hence the dilution of diffusing salts. Flux data is presented in Fig 2(a) and the full irradiance value is about $15 \mathrm{~L} \cdot \mathrm{m}^{-2} \cdot \mathrm{h}^{-1}$ which is in good agreement with the value determined at this pressure and flow with constant power (1). The membrane manufacturer presents a higher value for flux $52.7 \mathrm{~L} \cdot \mathrm{m}^{-2} \cdot \mathrm{h}^{-1}$, however this difference is justifiable since the feed water used in testing by the manufacturer is significantly lower concentration ( 2 g.L. $\mathrm{L}^{-1}$ $\mathrm{NaCl}$, at 15.5 bar) than the brackish water from the Pine Hill bore. As a result of this flux (and hence permeate flow) variation the volume of poor quality permeate is controlled reducing the overall risk of contamination.

Feed, permeate and concentrate conductivity is shown in Fig 2(b). While the permeate quality is generally well below the ADWG of $0.78 \mathrm{mS} . \mathrm{cm}^{-1}$ (TDS $500 \mathrm{mg} . \mathrm{L}^{-1}$ ) it is apparent that quality fluctuates with power and on occasion water quality exceeds the guidelines, notably near the beginning of the day. This can be explained with the flushing of stagnated water in the system and is of very brief duration as are spikes due to energy fluctuations. To examine this effect in more detail, a period of $10 \mathrm{~min}$ was recorded with high-resolution conductivity data (Fig. 3) to overcome the limitation of averaging by samples. Those results show - for the NF90 membrane due to lack of such data for the BW30 experiment - that despite a drop in power to $50 \%$, the fluctuation in permeate quality is minimal. These results show the reliability of the system with this particular membrane to produce high quality drinking water from brackish Pine Hill bore water for fluctuations of $50 \%$ on the solar irradiance hence during partial cloud coverage.

From those results one can now calculate recovery and retention, as shown in Fig 2(c). The average recovery was found to be $28 \%$ with high fluctuations due to variations of power which are most likely an artefact of the calculations given the highly variable feed and permeate flows on which such calculations are based. Except for very early in the morning 
the retention was found to be $95-100 \%$ (average of $96.6 \%$ ) based on the manual readings, which average out the performance somewhat

For the determination of actual system costs power consumption is an important parameter. The SEC values were found to vary from 1.9 to $2.6 \mathrm{kWh} \cdot \mathrm{m}^{-3}$ (refer Fig. 2(d)) with an average of $2.3 \mathrm{kWh} \cdot \mathrm{m}^{-3}$. This compares to an SEC of $1.8 \mathrm{kWh} \cdot \mathrm{m}^{-3}$ for the system operating with the BW30 membrane under constant power (resulting in a TMP of 11 bar and a feed flow of $400 \mathrm{~L}^{-1} \mathrm{~h}^{-1}$ (1). In an effort to explain the possible increase in SEC throughout the day, the 400 L.h $\left.{ }^{-1}\right)(1)$. In an effort to explain the possible increase in SEC throughout the day, the following increase in feed $\mathrm{EC}$ was exanhed in more detail. The feed concentration is $6 \%$ higher at the end of the day, rising from $8.1 \mathrm{mS} \mathrm{cm}^{-1}$ to $8.6 \mathrm{mS} . \mathrm{cm}^{-1}$. In addition, due to recycling of the permeate and concentrate, the feedwater temperature increased from $24.7^{\circ} \mathrm{C}$ at $6: 40$ to $32.1^{\circ} \mathrm{C}$ at $16: 09$ (a rise of $30 \%$ ) and then decreased back to $31.6^{\circ} \mathrm{C}$ at $17: 13$. The temperature response of the conductivity meter was checked with 5 g. $\mathrm{L}^{-1} \mathrm{NaCl}$ solution and found to display a fractionally lower reading at $32^{\circ} \mathrm{C}$ that at $25^{\circ} \mathrm{C}\left(\Delta \mathrm{EC}=-0.08 \mathrm{mS} . \mathrm{cm}^{-1}\right)$, The amo th of water lost in The amount of water lost in the sampling process is only small. The evaporation rate on was estimated to be $16.4 \mathrm{~mm} . \mathrm{d}^{-1}$ based on published Australian values (23) and a pan coefficien table (24). This corresponds to a maximum of $2 \mathrm{~L}$ of water evaporated from the reservoir used. Therefore, none of these mechanisms can explain the $6 \%$ increase in feed EC over the day.

While an increased SEC is expected at higher feed concentrations, the observed increase in SEC throughout the day is significantly greater (37\%) than the increase in feed EC. A significant increase in feedwater temperature would typically result in an increased flux through the membrane at a rate of $2.7 \% \cdot{ }^{\circ} \mathrm{C}^{-1}$ rise in water temperature (25). However, from Fig. 2, while there may be a very slight $(<10 \%)$ increase in flux between 9:00 and 15:00 (where the system is operating in a relatively stable manner) there is not a $20 \%$ increase in flux throughout the day as might be expected due to such an increase in feedwater temperature. The higher SEC at the end of the day (after 15:00) would result from the decreased flux due to the accumulation of precipitates on the membranes (membrane scaling/fouling). This was indeed observed more strongly during the solar continuous experiments (results not shown) and is related to the particularly difficult nature of this water. As noted in the first part of this paper (1), it is difficult to compare these SEC results with other published data due to several reasons. Firstly, the majority of brackish RE-membrane systems bave beentane systems have been the 26-28) and, secondly, other works have not used real brackish water supplies and have instead used $\mathrm{NaCl}$ solutions $(3,6,9,13,15,29)$. A further challenge is to compare the ability of this RE-membrane system to tolerate fluctuations in energy supply to other systems described in the literature, since the majority to date do not discuss temporal system performance $(3,6,8$ 11). Liu et al. (15) describe the response of a mechanically wind-powered RO system under fluctuating conditions. While the results look promising with valves and a pressure stabilization tank preventing the pressure from dropping below 5.2 bar, system robustness needs to be evaluated in the long term, while the authors noted that future work needs to focus on the use of real brackish water and pre-treatment to prevent membrane fouling.

In summary, the RE-membrane system described here exceeded the design criterion of being able to supply clean drinking water to a remote community with least 50 inhabitants. The hybrid system produced just over $1.1 \mathrm{~m}^{3}$ of permeate from brackish feedwater $\left(8.29 \mathrm{mS} . \mathrm{cm}^{-1}\right.$ conductivity) with an average conductivity of $0.21 \mathrm{mS}^{-\mathrm{cm}^{-1}}$, on a mostly-sunny day in October 2005. It is important to note that the results are representative of many tests during a six week period. The system exhibited an average recovery of $28 \%$ and an average SEC of $2.3 \mathrm{kWh} \cdot \mathrm{m}^{-3}$. The batteryless RE-membrane system is able to tolerate large fluctuations in solar irradiance $\left(500-1200 \mathrm{~W} \cdot \mathrm{m}^{-2}\right)$ with a minimal effect on permeate quality. While the initial SEC of $1.9 \mathrm{kWh} . \mathrm{m}^{-3}$ agrees well with experiments performed using a generator to obtain constant power, further experiments are necessary to better understand any apparent increases in both SEC and feedwater EC throughout the day. To this end, the RE-membrane system has been fitted with more robust sensors (flow, pressure, temperature, $\mathrm{pH}$, current, voltage, conductivity, solar irradiance) that can be logged at sub-second intervals to more accurately determine the transient nature of RE-membrane system operation. Future work will also aim to determine the system performance under heavy cloud, with solar irradiance levels in the range $0-500 \mathrm{~W} \cdot \mathrm{m}^{-2}$ as well as for operation with other renewable energy sources, continuous feed recharge and long term operation and most importantly the impact of variable power on the retention of various inorganic contaminants such as arsenic, fluoride, nitrate, boron and uranium.

\section{Acknowledgements}

In addition to contributions acknowledged in Part 1 of this series, we thank the School of Engineering and Physical Sciences (HWU) and the Nielson Fund (Mechanical Engineering) for a $\mathrm{PhD}$ studentship for Capão. 
Richards, B.S. ; Capão, D. ; Schäfer, A.I. ; (2008) Renewable energy powered membrane technology 2 The effect of energy fluctuations on performance of a photovoltaic hybrid membrane system, Environmental Science \& Technology, 42(12); 4563-4569. DOI: $10.1021 /$ es $703157 n$

(25) Alajlan, S. A.; Smiai, M. S. In Performance and development of PV-plant for water pumping and desalination for remote areas in Saudi Arabia, World Renewable Energy Congress, 1996; 1996; pp 441-446.

\section{References}

(1) Schäfer, A. I.; Broeckmann, A.; Richards, B. S. Renewable Energy Powered Membrane Technology. 1. Development and Characterization of a Photovoltaic Hybrid Membrane System. Environ. Sci. Technol. 2007, 41, 998-1003.

(2) Linden, D.; Reddy, T. B., Handbook of Batteries. 3rd ed.; McGraw-Hill: New York, 2002.

(3) Thomson, M.; Miranda, M. S.; Infield, D. A small-scale seawater reverse-osmosis system with excellent energy efficiency over a wide operating range. Desalination 2002, 153, (1-3), 229-236.

(4) Alsema, E. A. Environmental life cycle assessment of solar home systems; NWS-E-2000-15; Utrecht University: 2000.

(5) Thomas, M. G. Water Pumping: The Solar Alternative; SAND 87-0804; Sandia National Laboratories: 1987.

(6) Miranda, M. S.; Infield, D. A wind-powered seawater reverse-osmosis system without batteries. Desalination 2002, 153, (1-3), 9-16.

(7) Gocht, W.; Sommerfeld, A.; Rautenbach, R.; Melin, T.; Eilers, L.; Neskakis, A.; Herold, D.; Horstmann, V.; Kabariti, M.; Muhaidat, A. Decentralized desalination of brackish water by a directly coupled reverse-osmosis-photovoltaic-system - a pilot plant study in Jordan. Renewable

(8) Pestana, I. d. l. N.; Latorre, F. J. G.; Espinoza, C. A.; A.G., G. Optimization of RO desalination systems powered by renewable energies. Part I: Wind energy. Desalination 2004, 160, (3), 293

(9) Thomson, M.; Infield, D. Laboratory demonstration of a photovoltaic-powered seawater reverseosmosis system without batteries. Desalination 2005, 183, (1-3), 105-111.

(10) Mathew, K.; Dallas, S.; Ho, G. E.; Anda, M. In A solar-powered village water supply system from brackish water, World renewable energy congress VI, Brighton, 2000; Sayigh, A. A. M., Ed. Pergamon: Brighton, 2000; pp 2061-2064.

(11) Keefer, B. G.; Hembree, R. D.; Schrack, F. C. Optimized matching of solar photovoltaic powe with reverse osmosis desalination. Desalination 1985, 54, 89-103.

(12) Pritchard, C.; Verbeek, V.; Rahal, Z. A preliminary design of a direct-driven wind-powered SWRO system. Desalination \& Water Reuse 2003, 12, (4), 29-33.

(13) Robinson, R.; Ho, G.; Mathew, K. Development of a reliable low-cost reverse osmosis desalination unit for remote communities. Desalination 1992, 86, (1), 9-26.

(14) National Health and Medical Research Council (NHMRC) Australian Drinking Water Guidelines; MHMRC National Water Quality Management Strategy: Canberra, 2004.

(15) Liu, C. C. K.; Jae-Woo, P.; Migita, R.; Gang, Q. Experiments of a prototype wind-driven reverse osmosis desalination system with feedback control. Desalination 2002, 150, (3), 277287.

(16) Australia Bureau of Meteorology Laboratory and Radiation Sub-Section Solar Exposure Data 1947-2001 (NCCSOL), v2.209; 2002.

(17) Bureau of Meteorology Monthly Climate Summary - Northern Territory, October 2005. http://www.bom.gov.au/announcements/media_releases/nt/20051103.shtml (18 Feb 2008),

(18) Werner, M.; Schäfer, A. I. Social aspects of a solar-powered desalination unit for remote Australian communities. Desalination 2007, 203, 375-393.

(19) Dow Water Solutions Membrane datasheet FilmTec BW30-4040. http://www.dow.com/PublishedLiterature/dh_0059/0901b803800597a8.pdf (18 Feb 2008).

(20) Dow Water Solutions Membrane datasheet FilmTec NF90-4040. http://www.dow.com/PublishedLiterature/dh_0074/0901b803800749de.pdf (18 Feb 2008).

(21) Hydranautics Membrane datasheet ESPA4-4040. http://www.hydranautics.com/docs/4inch/ESPA4-4040.pdf (18 Feb 2008).

(22) Koch Membrane Systems Membrane datasheet TFC-S. http://www.kochmembrane.com/pdf/8492000spiral.pdf (18 Feb 2008).

(23) Manins, P.; Allan, R.; Beer, T.; Fraser, P.; Holper, P.; Suppiah, R.; Walsh, K. Atmosphere: Australia State of the Environment Report 2001; CSIRO Publishing on behalf of the Department of the Environment and Heritage: Canberra, 2001; p 46.

(24) Shuttleworth, W. J., Chapter 4 - Evaporation. In Handbook of Hydrology, Maidment, D. R., Ed McGraw-Hill: 1993.
(26) Joyce, A.; Loureiro, D.; Rodrigues, C.; Castro, S. Small reverse osmosis units using PV systems for water purifications in rural places. Desalination 2001, 137, 39-44.

(27) Al Suleimani, Z.; Nair, V. R. Desalination by solar-powered reverse osmosis in a remote area of the Sultanate of Oman. Applied Energy 2000, 65, (1-4), 367-380.

(28) Badreddin, E.; Gambier, A.; Aboul-Fotouh, F. Laboratory set-up for education and research on automation of reverse osmosis plants employing a sustainable energy source. Desalination 2004, 166, 307-314.

(29) Masson, L.; Richards, B. S.; Schäfer, A. I. System design and performance testing of a hybrid membrane photovoltaic desalination system. Desalination 2005, 179, 51-59.

\section{Table Captions}

Table 1 Summary of weather conditions and test results for experiments performed with the RE-membrane system at Pine Hill Station equipped with four different NF/RO membranes (BW30, NF90, ESPA4, TFC-S) on different days in October 2005. The solar irradiance and permeate volume (both integrated over the day) are displayed, along with average values for flux, retention, recovery, TMP, permeate EC, concentrate EC, and SEC.

Table 2 Performance comparison of RE-membrane system at Pine Hill Station equipped with four different NF/RO membranes (BW30, NF90, ESPA4, TFC-S) under similar climatic conditions near the middle of the day. Instantaneous values for all of the following parameters are displayed: solar irradiance, flux, retention, recovery, TMP, permeate EC, concentrate EC, SEC and permeate flow rate. 
Richards, B.S. ; Capão, D. ; Schäfer, A.I. ; (2008) Renewable energy powered membrane technology 2 The effect of energy fluctuations on performance of a photovoltaic hybrid membrane system,

Environmental Science \& Technology, 42(12); 4563-4569.

DOI: 10.1021/es703157n

Table 1

" permeate flow sensor was operating very intermittently this day.

\begin{tabular}{|c|c|c|c|c|c|c|c|c|c|c|c|}
\hline Membrane & Date & Weather & $\begin{array}{l}\text { Solar } \\
\text { Irradiance }\end{array}$ & Flux & Retention & Recovery & TMP & $\begin{array}{l}\text { Perm. } \\
\text { EC }\end{array}$ & Conc. EC & SEC & $\begin{array}{c}\text { Daill. } \\
\text { Perm. } \\
\text { Vol. }\end{array}$ \\
\hline & & & $\mathrm{kWh} \cdot \mathrm{m}^{-2} \cdot \mathrm{d}^{-1}$ & $\mathrm{~L} \cdot \mathrm{m}^{-2} \cdot \mathrm{h}^{-1}$ & $\%$ & $\%$ & bar & mS.cm ${ }^{-1}$ & $\mathrm{mS} . \mathrm{cm}^{-1}$ & kWh.m- & $\mathrm{L}$ \\
\hline BW30 & 7.10 .05 & 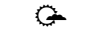 & 9.5 & 15.4 & 96.6 & 28.1 & 8.9 & 0.28 & 10.2 & 2.3 & 1106 \\
\hline NF90 & 9.10 .05 & $c$ & 9.7 & 22.1 & 93.7 & 42.6 & 9.6 & 0.52 & 12.8 & 1.5 & 1355 \\
\hline ESPA4 & 12.10 .05 & $\because$ & 6.8 & 22.7 & 90.1 & 38.7 & 7.3 & 0.81 & 13.4 & 1.5 & 848 \\
\hline TFC-S & 16.10 .05 & m & 7.2 & 14.6 & 73.2 & 37.8 & 8.4 & 2.12 & 14.6 & 1.3 & $\mathrm{n} / \mathrm{a}^{*}$ \\
\hline
\end{tabular}

\section{Table 2}

\begin{tabular}{|c|c|c|c|c|c|c|c|c|c|c|c|}
\hline Membrane & \multirow{2}{*}{ Time } & Weather & $\begin{array}{c}\text { Solar } \\
\text { Irradiance }\end{array}$ & Flux & Retention & Recovery & TMP & $\begin{array}{c}\text { Perm. } \\
\text { EC }\end{array}$ & Conc. EC & SEC & $\begin{array}{c}\text { Perm. } \\
\text { Flow } \\
\text { rate }\end{array}$ \\
\cline { 4 - 13 } \\
\hline BW30 & $12: 00$ & O & 1040 & 17.0 & 97.9 & 28.9 & 10.9 & 0.17 & 10.5 & 2.4 & 122 \\
\hline NF90 & $11: 00$ & $\bigcirc$ & 1018 & 24.8 & 94.9 & 42.1 & 10.8 & 0.42 & 13.7 & 1.5 & 188 \\
\hline ESPA4 & $12: 13$ & $\bigcirc$ & 1121 & 30.6 & 94.1 & 46.8 & 10.4 & 0.47 & 14.8 & 1.5 & 241 \\
\hline TFC-S & $11: 37$ & $\bigcirc$ & 1085 & 26.0 & 76.7 & 57.5 & 11.9 & 1.80 & 15.8 & 1.4 & 187 \\
\hline
\end{tabular}


Richards, B.S. ; Capão, D. ; Schäfer, A.I. ; (2008) Renewable energy powered membrane technology 2 The effect of energy fluctuations on performance of a photovoltaic hybrid membrane system, Environmental Science \& Technology, 42(12); 4563-4569.

DOI: $10.1021 / \mathrm{es} 703157 \mathrm{n}$

\section{Figure Captions}

Figure 1 (a) Pump power as fluctuation of solar irradiance (both tracked - versus fixed ----) throughout the solar day. This results in (b) a varying feed flow - equivalent to UF permeate flow - and (c) a transmembrane pressure (TMP).

Figure 2 (a) Flux; (b) Permeate (•), feed (॰), and concentrate (o) electrical conductivity (EC); (c) Recovery (•) and salt retention (•); and (d) Specific energy consumption (SEC) plotted as a function of solar irradiance fluctuation throughout the solar day.

Figure 3 Permeate conductivity for a short period of high solar irradiance fluctuation for NF90 membrane between 12:30 and 12:40 on 09.10.2005.

\section{Figure 1}

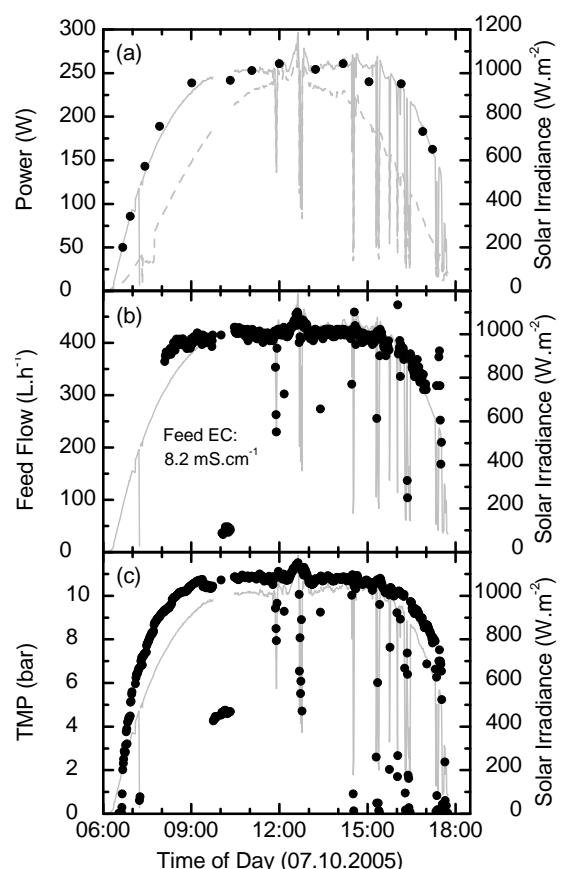


Richards, B.S. ; Capão, D. ; Schäfer, A.I. ; (2008) Renewable energy powered membrane technology 2 The effect of energy fluctuations on performance of a photovoltaic hybrid membrane system, Environmental Science \& Technology, 42(12); 4563-4569.

DOI: 10.1021/es703157n

\section{Figure 2}

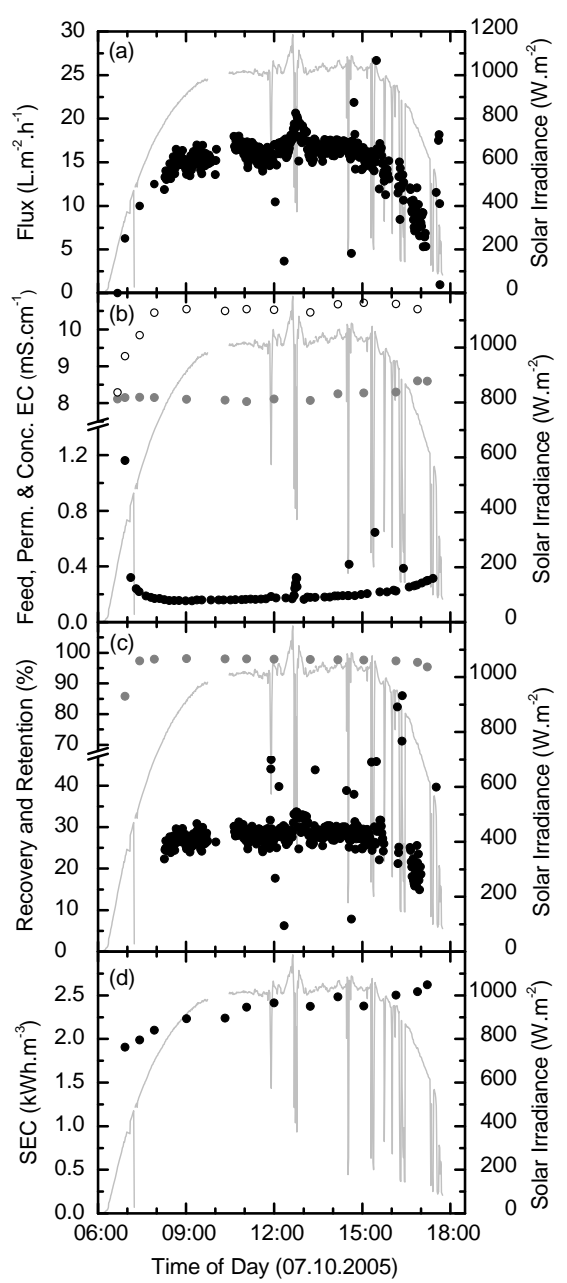

\section{Figure 3}

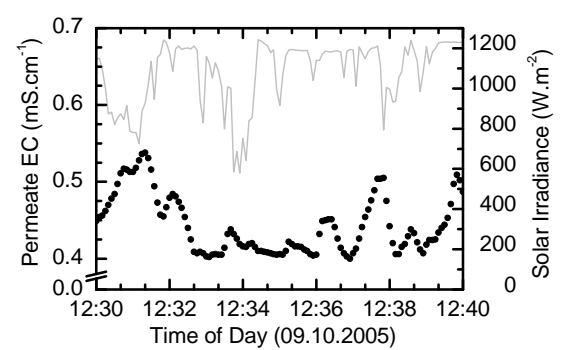

